\title{
Improving the Competence in Using Punctuation Marks for English Majors through Reading Academic Texts
}

\author{
Tran Thi Yen \\ Faculty of Foreign Languages Education, Thai Nguyen University of Education, Vietnam \\ DOI: 10.29322/IJSRP.11.12.2021.p12025 \\ http://dx.doi.org/10.29322/IJSRP.11.12.2021.p12025
}

\begin{abstract}
The aim of the present research is to investigate the effects of reading academic reading texts on improving the competence in using punctuations marks in English academic writing for third-year English majors at Thai Nguyen University of Education. To achieve the aim of the research, we chose 40 students, who volunteered to take part in the study; 20 of them were assigned to the experimental group and the other students assigned to the control group. The two groups had to respond to the pre-questionnaire. For the experimental group, the researcher asked them to outline usages of punctuation marks, read academic texts, underline the examples of punctuation marks and write their own examples. Besides, they also did some exercises to practice using punctuations marks in English academic writing. Data of the research was collected within 6 months form the pre-questionnaire, post-questionnaire, pre-test and post-test before and after the experiment. The results of the study indicate that the experimental group advanced remarkably in using punctuations marks compared to the control group. This demonstrates that reading academic reading texts has a positive effect on students' competence in using punctuation marks in academic writing. Additionally, feedback from the experimental group was almost positive regarding the use of academic reading texts for improving their competence in using punctuations marks. Finally, some suggestions have been made to overcome the limitations and enhance the potential of using academic reading texts for improving learners' punctuation competence.
\end{abstract}

Index Terms- punctuation, punctuation competence, academic reading texts, academic writing, English major.

\section{INTRODUCTION}

In the English learning process, there are four skills that must be mastered by learners, including speaking, listening, reading and writing. Writing is one of the important skills which can help students a lot in developing their English proficiency by expressing their knowledge as well as experiences. Writing can be done in the form of a paragraph, an essay, a letter, a report, an article or a short story. A good piece of writing involves several elements like vocabulary and grammar. However, in the aspect of grammar, punctuation was often paid little attention to. Meanwhile, employing proper punctuation marks is very important in writing since it can help conveys complete meanings (Oshima \& Hogue, 2006). Punctuation is not only an essential part of forms of written communication from academic essays to letters, but it also helps the writer achieve powerful stylistic effects if used well. All writers need to be able to understand the rules of punctuation use if they are to write effectively. The importance of punctuation appears when it is assumed that syntactical structure is not enough to display the intended meanings, and this is the strong reason to use punctuation. When syntax fails in making the meaning clear, then punctuation is to show the sense that someone wants. The punctuations that are commonly used are periods, commas, colons, exclamations, question marks, apostrophes, and quotation marks. It is difficult to understand the meaning of texts if we use punctuations incorrectly.

Learners make errors of using punctuation regularly. The errors happen because English is not their native language. There are also different rules of English regarding their native language; consequently, the errors are frequently committed. Punctuation errors occur in the form of omission or misuse of punctuation marks. To know students' difficulties in using punctuations, teachers need to analyze the reasons why their students made such errors. This method is often referred to as error analysis. Lack of accuracy, omission, and misuse of punctuation are some of the problems faced by students. Failure to use punctuations will result in confusing meanings and even unsuccessful communication. This is why the lecturers and the students must pay attention to using punctuation marks properly in academic writing.

Based on the explanations above, the researcher conducted the research: "Improving the competence in using punctuation marks in English academic writing for English majors through academic reading texts". In this study, the researcher tried to identity the types and the causes of punctuation errors committed by students in writing academic English, and then conducted an experiment, in which the research introduced the use of academic reading texts in improving the competence of using punctuation marks for English majors in writing academic English. 


\section{LITERATURE REVIEW}

\subsection{Key concepts}

\section{Punctuation marks}

Punctuation is the use of special marks to separate phrases and sentences, to show that something is a question, a statement or an exclamation. Using punctuation marks is very important because it can make the readers to easily understand the meaning in writing even without looking at the expression of the person who wrote the message. To write well, learners must punctuate well, but to punctuate well learners must also write well. The functions of punctuation marks are to separate words and phrases within a sentence according to their meanings.

Punctuation marks help show not only the structure and organization of a piece of written work but also the intonation and pauses when it is read aloud. In written English, punctuation marks are very important to express the meaning of sentences. The rules of punctuation are different in different languages, regions, periods of time and they are continually evolving. Some aspects of punctuation are stylistic; therefore, the choice of a specific sometimes depends on the writer. The most commonly used punctuation marks in English are full stop or period (.), question mark (?), exclamation mark (!), comma (,), colon (:), semi colon (;), quotation marks (“"'), hyphen (-), apostrophe ('), parentheses (), square brackets ([]), and slash (/). Each of these punctuation marks indicates a different thing, and some may have multiple meanings depending on the context.

\section{Functions of punctuation marks}

Phonetic Function: Punctuation marks show clearly the rhythm, pauses, and tone in a written document. Many the times the tone is ignored, and the readers are free to interpret the tone the way they feel like. This may lead to confusing situations, and it is worse than grammatical mistakes.

Grammatical Function: Punctuation marks can be used to mark statements, indicate interrogations; indicate emphatic content; build the structure of a sentence, complex sentence, paragraph or documents, etc.

Semantic Function: Punctuation marks help the audience (either listeners or readers) understand the meaning of a specific word, phrase, sentence and even paragraph by marking them differently than normal text. Wrong use of punctuation marks can hinder understanding and break the flow of ideas; meanwhile proper utilization of punctuation marks can help the audience understand the author's meaning and draw their attention to the written work. (Rumki, 2005).

\section{Academic writing}

According to Oshima (2004), academic writing is a kind of writing normally done in college or university. Academic writing is formal and follows some standard conventions. Academic writing or nonfiction writing is produced as part of academic work. Academic writing is characterized by evidence-based arguments, precise word choice, logical organization, and an impersonal tone. It informs, analyzes, and persuades in a straightforward manner and enables the reader to engage critically in a scholarly dialogue.

\section{Academic reading text}

An academic text can be defined as critical, objective, specialized texts written by experts or professionals in a given field using formal language. Academic texts are objective. This means that they are based on facts with solid basis. The emotions of the authors cannot be felt from texts or materials. Academic texts often take years to publish because of intense writing and review.

An important feature of academic texts is that they are organized in a specific way; they have a clear structure. This structure makes it easier for the reader to navigate the text and understand the material better. It also makes it easier for the reader to organize the material. The structure of an academic text should be clear throughout the text and within each section, paragraph and even sentence.

\subsection{Previous research}

Several studies have been conducted by some experts with regard to error analysis method in using punctuation. Meyer (1985) found that educators see punctuation accuracy as the difference between "good" writing and "bad" writing. He added that writing an easy requires students to use various punctuation marks correctly to help the reader construct the intended meaning of each sentence appropriately and meaningfully. Rumki (2005) stated that wrong punctuation can interrupt the flow of ideas and change meaning, but properly used punctuation not only helps readers understand the meaning but also makes them engrossed in one's writing.

Robinson (2002) stated that good punctuation makes a lot for clear thought. A mania for punctuation is also an occupational hazard for almost any teacher; he added that the rules are important. Nurhayati (2013) investigated students' errors in using punctuation marks in written English. The results show that the comma was the most common errors committed by students. She also found that the errors happened because of carelessness and lack of high personal standard of excellence. Benjamin and Akampirige (2014) carried out the research on errors while using the comma, colon and semicolon. The results show that these errors were just due to ignorance. Al-Mutib (1989) found out that the use of punctuation marks and the semicolon to connect two related clauses is very rare. In addition, the comma was often inappropriately used to link two clauses, which results in so-called run-on sentences. 
Wilde (1992) emphasized that readers have trouble understanding written English because of the lack of commas; they have to go back and re-read a certain section of the written work to get the full gist. Khalil (2000) mentioned that the most common errors committed by Palestinian EFL students in their writing are commas and periods. The most common errors are categorized into comma splice and superfluous commas. Superfluous commas errors refer to over punctuating sentences by inserting commas in the wrong place. Ahmed Awad (2012) conducted the study "The Most Common Punctuation Errors committed by the English and theTEFL Majors at An-Najah National University". The results revealed that the most common errors among the English and the TEFL majors at An-Najah University were the overuse of comma at the expense of the period, the incorrect use of the capital letter, the wrong use of the quotation marks and the misuse of semicolon respectively. Huda. D. Salman, May Estefan and Nahi. Y. Yaseen (2017) carried out a research project entitled "Errors in Using Punctuation Marks in Selected Scientific Writing Committed By Non- Native Postgraduate". The results reveal that there are errors in using punctuation marks made by non-native postgraduates.

To clearly and accurately identify the common errors related to punctuation in academic writing, and to improve the competence of using punctuation marks for English majors in writing academic English, the researcher conducted the study: "Improving the competence in using punctuations marks in English academic writing for English-majors through academic reading texts". In this study, we aimed to investigate the current situation of using punctuation marks, identify students' common punctuation errors and the causes of these errors to help students advance punctuation usage and use it correctly.

\section{METHODOLOGY}

\subsection{Research questions}

The study aimed at answering the following research questions:

- What is the current situation of using punctuation marks among third-year English majors at Thai Nguyen University of Education?

- To what extent does reading academic texts have effects on enhancing the competence in using punctuation marks for third-year English majors at Thai Nguyen University of Education?

\subsection{Research methods}

The research was done based on mixed methods because it combined experimental method and quantitative method. First of all, an experiment was implemented to examine the effects of reading academic texts on enhancing the competence in using punctuation marks. In addition, the quantitative method was employed with questionnaires to collect data and learners' feedback toward reading academic texts to strengthen their competence in using punctuation marks. An integrated research strategy is necessary to produce more reliable results with regard to quality and scope.

\subsubsection{Experimental method}

An experiment was implemented to examine the impacts of reading academic texts on learners' competence in using punctuation marks. The experiment was conducted during the first semester of the academic year 2019-2020. First, the researcher asked the experimental group to outline the usages of punctuation marks. After that, the researcher required the experimental group to read academic texts three to four times a week, underline examples about the usage of punctuation marks and write their own examples. Then, the researcher also designed some more exercises to help the experimental group remember the usages of punctuation marks and how to use punctuation marks correctly in some common situations. The researcher created a class on Edmodo and asked the experimental group to submit the file of academic reading texts, their own examples and all the completed exercises so that the researcher could control their learning process and progress.

In addition, the experimental method was the Pretest-Posttest design, which was widely used for the purpose of comparing groups and measuring changes resulting from the experimental treatment. The researcher constructed the basic pretest-posttest experimental design in which the experimental group learned the usages of punctuation marks through reading academic reading texts and then compared their progress to that of the control group who were taught punctuation marks without reading academic texts. Moreover, the pre-test and post-test were judged by an expert to ensure the accuracy and validity.

\subsubsection{Quantitative method}

The questionnaire survey was chosen as a data collection instrument in the quantitative approach. The quantitative method was employed in our research in order that we could have a panorama of students' competence in using punctuation marks, their attitudes towards reading academic texts to improve their competence in using punctuation marks and their suggestions to improve the effectiveness of utilizing reading academic texts in using punctuation marks.

\subsection{The participants}

The participants of this study were English majors at Thai Nguyen University of Education ranging in the same age group of 21-22 years. They were third-year students. The total number of participants was 40 . These third-year English majors were crucial 
participants in the study as they took the pretest, the posttest and responded to the questionnaires to help the researcher collect sufficient data to answer the research questions.

The participants were divided into 2 groups: the experimental group and the control group. The primary reason for choosing the participants from the third-year English students was that the research would like to help them recognize the significance of punctuation marks, hence improving the other English skills such as reading and writing. Indeed, punctuation marks had considerable impacts on writing. Thus, the researcher would like to accommodate students with valuable materials to assist them in enhancing their competence in using the punctuation marks in academic writing.

The experimental group included 20 students who volunteered to join the study. They were experimented with the new method on using punctuation marks. The researcher created a class on Edmodo and required the students to create their own account and join the class. First, the researcher asked the experimental group to outline the usages of punctuation marks. After that, the researcher required the experimental group to read academic texts three to four times a week, underline examples about the usage of punctuation marks and write their own examples. Then, the researcher also designed some more exercises to help the experimental group remember the usages of punctuation marks and how to use punctuation marks correctly in some common situations. The researcher asked the experimental group to submit the file of academic reading texts, their own examples and all the completed exercises so that the researcher could control their learning process and progress. Meanwhile, the control group's members only took the pretest, posttest and responded to the pre-questionnaire.

\subsection{Data collection instruments}

\subsubsection{Tests}

Pre-tests and post-tests were employed in the study. The pre-test was administered to identify the errors committed by students in using punctuation marks. The researcher asked the students to write an essay of about 250 words. They were given forty minutes to complete their essay. Then, the researcher collected the essays. The post-test of similar format was conducted after the experiment had been completed.

\subsubsection{Questionnaires}

A pre-experiment questionnaire was administered to both control group and experimental group at the beginning of the experimental time. A post-experiment questionnaire was given to only the experimental group at the end of the experimental time. In the design of the questions, the researcher combined two types of items: open-ended questions and close-ended questions. The researcher applied open-ended questions to exploit more information from the respondents.

\subsubsection{Writing analysis}

In order to find out the punctuation errors committed by third-year English major at TNUE, the researcher collected 60 academic writings which were written by 40 third-year English majors in the pre-test at the beginning of the $2019-2020$ academic year. The goal of writing analysis was to identify the types and the frequency of punctuation errors in students' academic writings.

After the experiment, the researcher continued to collect 40 writings ( 20 from the experimental group and 20 from the control group) to identify the errors and compare the number of errors between the two groups as well as compare the number of errors committed before and after the experiment.

\section{RESEARCH RESULTS ANALYSIS AND DISCUSSION}

\subsection{The current situation of using punctuation marks by third-year English majors at Thai Nguyen University of Education}

\subsubsection{Data from the survey pre-questionnaire}

The pre-questionnaire for 60 students which was delivered before the experiment consists of nine questions. The researcher aimed to gather data concerning students 'opinions about the importance of punctuation marks in academic writing; students' attention to punctuation marks; students' view about making punctuation errors in academic writing; the difficulties students encounter when they use punctuation marks; the ways students use to improve the usage of punctuation marks; students' opinion about the necessity of academic reading texts in improving students' competence in using punctuation marks; the benefits academic passages bring to students' competence in using punctuations marks.

The results from the prequestionnaire can be summarized as follows: Almost all of the participants said that punctuation marks are important in academic writing as they are important tools to make the writing logical and readable. $65 \%$ of the participants said that when they write an essay, they pay attention to punctuation marks; only 35\% of the students revealed that they do not pay attention to punctuation marks when they write an essay. $81 \%$ of the participants indicated that they often make punctuation errors in academic writing; only $18 \%$ of the students said that they do not make punctuation errors in academic writing.

Regarding the main difficulties in using punctuation marks, nearly half of the students said that they place the punctuation marks incorrectly. Omitting the punctuation marks is the second difficulty students faced when they use punctuation marks. A quarter 
of the participants showed that they confuse the usage of some punctuation marks in some situations. $15 \%$ of the students do not know how to use different punctuation marks. Only $5 \%$ of the participants indicated that they do not have suitable methods to practice.

Concerning the ways students use to improve the usage of punctuation marks, $72 \%$ of the students said that they try to remember all the usages of punctuation marks; $27 \%$ of the participants revealed that they make some examples for each usage; $22 \%$ of the students read some materials about using punctuation marks effectively.

About the use of academic passages for improving students' competence in using punctuation marks, $95 \%$ of the participants said that they had never regarded academic texts as a method for improving their competence in using punctuation marks. Only $5 \%$ of the students replied that they had ever used this method. Most of the participants (90\%) expected that reading academic text is useful in improving their competence in using punctuation marks. More than half of the students indicated that reading academic texts may help them learn the usage of punctuation marks from reliable sources. 38\% of the participants said that by reading academic texts, they can see examples of punctuation marks in some common situations. $27 \%$ of the participants revealed that they may have more chances to write their own examples based on the examples in academic readings.

\subsubsection{Data from writing analysis}

The researcher collected and analyzed 40 essays written by the participants in the pre-test. The writing analysis results show that almost all students made punctuation errors when they wrote an essay. The comma was the kind of punctuation marks which students made the most frequently, and the second commonly committed mistake is related to the semicolon.

In conclusion, based on the data attained from the questionnaire and the writing pre-test, it is obvious that students encounter many difficulties in using punctuation marks in academic writing. Almost all students only try to remember the usage of punctuation marks without doing exercises and making examples related to the punctuation marks. Besides, reading academic texts to improve the competence in using the punctuation marks is not commonly applied by most of the third-year English majors. Therefore, it is necessary for students to discover a useful method to help them improve their competence in using the punctuation marks.

\subsection{The impact of reading academic texts on enhancing the students' competence in using punctuation marks}

\subsubsection{Results of the pre-test and post-test}

Table 1 compares the frequency of punctuation errors committed by the students in the control group and the experimental group in the pre-test and the post test.

Table 1. The frequency of punctuation errors committed by the students

\begin{tabular}{|c|c|c|c|c|c|}
\hline \multicolumn{2}{|c|}{$\begin{array}{c}\text { Experimental Group } \\
\text { (SE= student of the }\end{array}$} & \multicolumn{3}{c|}{$\begin{array}{c}\text { Control Group } \\
\text { experimental group) }\end{array}$} & \multicolumn{3}{c|}{ group) } \\
\hline Students & Pre-test & Post-test & Students & Pre-test & Post-test \\
\hline SE1 & 5 & 2 & SC1 & 5 & 4 \\
\hline SE2 & 4 & 1 & SC2 & 4 & 3 \\
\hline SE3 & 3 & 2 & SC3 & 2 & 4 \\
\hline SE4 & 3 & 0 & SC4 & 4 & 3 \\
\hline SE5 & 2 & 0 & SC5 & 5 & 3 \\
\hline SE6 & 3 & 1 & SC6 & 4 & 2 \\
\hline SE7 & 3 & 0 & SC7 & 3 & 5 \\
\hline SE8 & 4 & 1 & SC8 & 4 & 4 \\
\hline SE9 & 5 & 2 & SC9 & 4 & 3 \\
\hline SE10 & 1 & 0 & SC10 & 5 & 2 \\
\hline SE11 & 3 & 0 & SC11 & 3 & 3 \\
\hline SE12 & 4 & 2 & SC12 & 3 & 5 \\
\hline SE13 & 4 & 1 & SC13 & 1 & 4 \\
\hline SE14 & 5 & 0 & SC14 & 4 & 3 \\
\hline SE15 & 4 & 1 & SC15 & 4 & 3 \\
\hline SE16 & 2 & 0 & SC16 & 5 & 4 \\
\hline SE17 & 5 & 2 & SC17 & 5 & 3 \\
\hline SE18 & 4 & 2 & SC18 & 3 & 1 \\
\hline SE19 & 3 & 0 & SC19 & 4 & 3 \\
\hline SE20 & 3 & 1 & SC20 & 3 & 4 \\
\hline
\end{tabular}


From the table, it is obvious that almost all students made lots of punctuation errors. The number of punctuation errors committed by the students fluctuated between 1 and 5 .

After reading academic texts to enhance the competence in using punctuation marks, the researcher let the students do the posttest. The post-test was designed with the same level and structure as the pre-test. After the experiment, the students' competence in using punctuation marks is improved significantly; there are some students who did not make any error when they wrote their essay.

As stated in the methodology chapter, students of the control group also took the post- test. As can be clearly seen from the table, compared with the result of the pre-test, students' competence in using punctuation marks was improved slightly.

Table 2 revealed the total number of punctuation errors committed by the students of both groups in the pre-test and post-test.

Table 2. The total number of punctuation errors

\begin{tabular}{|c|c|c|c|}
\hline Test & Group & Total punctuation errors & Average \\
\hline Pre- & Experimental & 70 & 4 \\
\cline { 2 - 4 } Test & Control & 69 & 3 \\
\hline Post & Experimental & 18 & 1 \\
\cline { 2 - 4 } Test & Control & 68 & 3 \\
\hline
\end{tabular}

A glance at the table provided above reveals that there is a significant difference between the total number of punctuation errors in the pre-test and post-test of the participants in the experimental group. In fact, in the pre-test, the total number of punctuation errors is 70; however, in the post-test, the total number of punctuation errors is 18 . The difference is remarkable. On average, in the pre-test, one student of the experimental group made 4 mistakes; however, in the post-test, he or she made only one mistake.

Meanwhile, there is an unremarkable gap between the total number errors in the pre-test and post-test of the 20 students in the control group. On average, in the pre-test, each student from the control group committed three punctuation errors, and in the post-test they still committed several errors (three errors).

To evaluate the improvements of the two groups after the experiment, the researcher used SPSS statistical analysis to show the impact of reading academic texts on students' competence in using punctuation marks. The result are shown in Table 3.

Table 3. Results of Paired Samples Test

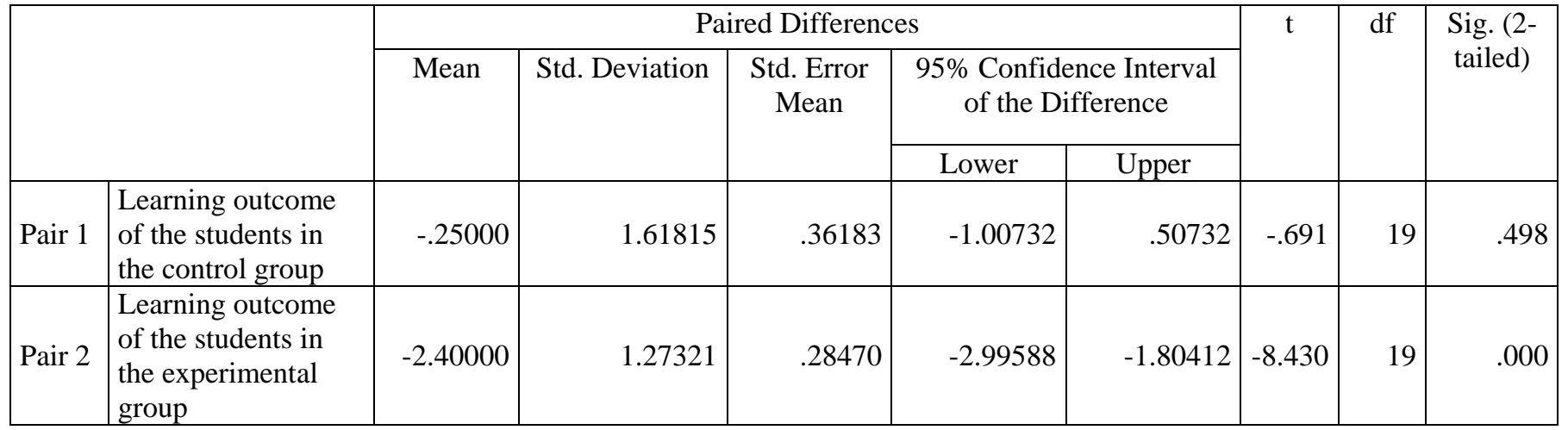

In the table, the researcher mainly focused on Sig. (2-tailed) which is the result of P-value when comparing Pair 1 with Pair 2. The figures in Sig. (2-tailed) have relationship with hypothesis H0, which reveals that there is no difference in results of pre-test and post-test. Based on the figures in Sig. (2-tailed) column, it can be seen that:

$$
\text { Pair 1: } P=0.498>0.05 \text { ( } p \text {-value) }
$$

It demonstrates that the hypothesis $\mathrm{H} 0$ was accepted. In other word, there is no difference between the results of the pre-test and post-test of the control group.

$$
\text { Pair 2: } P=0.000<0.05(p \text {-value })
$$

It means that the results in the pre-test and post-test scores of the experimental group have changed significantly and the hypothesis $\mathrm{H} 0$ was totally rejected. In other words, the result in Sig. (2-tailed) strongly proved that reading academic texts has a positive impact on students' competence in using punctuation marks. 
To put it another way, there is a significant difference between the pre-test and post-test results of the participants in the experimental group while there is an unremarkable gap between the number of errors in the pre-test and post-test of the 20 students in the control group. This demonstrates that although the experiment was implemented in a short time of 6 months, the participants' competence in using punctuation marks is improved considerably.

\subsubsection{Results of the post-questionnaire}

The post-questionnaire aims to gather information related to students' preference of reading academic texts to improve their competence in using the punctuation marks; the benefits that reading academic texts can bring to learners; students' prospect about the possibility of reading academic texts to improve the competence in using punctuations marks; and suggestions for enhancing the use of academic texts to improve students' punctuation competence

The results from the post-questionnaire show that $90 \%$ of the students stated that reading academic texts is easy to learn and their competence is improved. There were only $10 \%$ of the participants who said that they would not read academic texts to improve the competence in using punctuation marks. Most of the students indicated that they found reading academic texts an interesting source for them to improve their competence in using the punctuation marks. They also stated that reading academic texts brings many benefits to students in their process of using the punctuation marks. $40 \%$ of the students stated that they can learn the usage of punctuation marks from reliable sources. $32 \%$ of the participants said that they see the examples of punctuation marks in some common situations. Besides, $24 \%$ of the participants revealed that they can have more chances to write their own examples based on examples in academic readings. Moreover, $48 \%$ of the participants showed that they feel comfortable while reading academic texts.

Most of the students in the experimental group (19 students) hoped that their teacher will use reading academic texts to teach them punctuation marks at school regularly. Instead of the traditional methods, teachers can apply reading academic texts to promote students' competence in using the punctuation marks at school. Almost all of the participants (95\%) indicated that they will continue to use reading academic texts to improve their competence in using the punctuation marks. Students can use reading academic texts as an effective tool to enhance the punctuation marks significantly.

Nearly half of the participants agreed that they will usually continue use reading academic texts to enhance the competence in using punctuation marks. $30 \%$ of the students indicated that they will always use reading academic texts as a useful tool to enhance their competence in using the punctuation marks. $25 \%$ of the participants said that sometimes they use reading academic texts to improve their competence the punctuation marks. In particular, no students chose the category of "Never".

Nearly half of the students can improve using the punctuation marks by reading academic texts and write examples every day. $32 \%$ of the students said that they will try to take notes of more about examples related punctuation marks. Nearly a quarter of the participants indicated that they may read many different materials to enhance their competence in using the punctuation marks.

In summary, by analyzing the results of tests and questionnaire responses gathered, the researcher realizes that students 'competence in using the punctuation marks is improved significantly through reading academic texts. Besides, students have more chances to practice the usage of the punctuation based on doing exercises and they may write their own examples. Moreover, the new method also stimulates students 'interest and desire to use the punctuation marks correctly. To put it another way, students still keep a positive attitude and want to continue to read academic texts as a useful tool to enhance their competence in using the punctuation marks.

\section{CONCLUSION}

Based on the results collected from the pre-test, post-test, writings and student survey questionnaire, the researcher would like to summarize as well as make some recommendations to help students improve their competence in using the punctuation marks.

Firstly, the present study aims to identify students' difficulties in using punctuation marks in academic writing. Students often make punctuation errors when they write an essay. They often place the punctuation marks incorrectly or omit the punctuation marks. On the other hand, they only try to remember the usages of punctuation marks; they do not have more chances to do exercises and make their own examples to remember longer. Therefore, they show weakness in the competence of using punctuation marks. Furthermore, they do not have suitable methods to practice and they often feel disappointed when they use punctuation marks in an essay. Being aware of the importance of punctuation marks in academic writing, the researcher carried out a research to help students improve their competence in using punctuation marks in academic writing. The researcher was entitled "Improving the competence in using punctuations marks in English academic writing for third-year English majors at Thai Nguyen University of Education through academic reading texts". Thanks to reading academic texts, students have more opportunities to enhance their competence in using punctuation marks; moreover, they advance punctuation usages and use it correctly.

It is obvious that reading academic texts affects students' competence in using punctuation remarkably. They learn the usage of punctuation marks from reliable sources and see the examples of punctuation marks in some common situations. Besides, they have chances to write their own examples based on examples in academic texts. Especially, students feel excited when they read academic texts to enhance the competence in using punctuation marks. Besides, there is a big difference between the total number of punctuation errors in the pre-test and post-test of participants in the experimental group while there is an insignificant gap between pre-test and post-

This publication is licensed under Creative Commons Attribution CC BY.

http://dx.doi.org/10.29322/IJSRP.11.12.2021.p12025

WWW.ijsrp.org 
test of the students in the control group. This demonstrates that the participants' competence in using punctuation marks is improved when reading academic texts. Students have made a lot of progress in using punctuation marks correctly. In the control group, the improvement in using punctuation marks seems to be unremarkable. Finally, by collecting and analyzing the date from the postquestionnaire, the researcher found out that students are excited when they read academic texts to improve their competence in using punctuation marks. They also indicated that reading academic texts makes using punctuation marks become more efficient. Furthermore, they would like to continue to use academic texts as useful material to improve the competence in using punctuation marks. Students also hope that their teacher can apply this new method to teach them punctuation marks.

\section{References}

[1] Akampirige, A. O. M \& Benjamin, A. (2014). Errors in the use of punctuation marks among polytechnic students. International journal of english language and literature studies errors in the use of punctuation marks among polytechnic students.

[2] Al-Mutib, Saleh. (1989). Punctuation and reading comprehension among seventh and eighth grade students in a university lab school: an assessment. Ph.D. Florida State University

[3] Awad, A. (2012). The Most Common Punctuation Errors committed by the English and the TEFL Majors at An-Najah National University.

[4] Huda. D. Salman, 2. M. (2017). Errors in Using Punctuation Marks in Selected Scientific Writing Committed By Non- Native Postgraduate.

[5] Khalil, A. (2000). Analysis of Errors committed by Arab EFL Learners. Bethlehem University. Palestine. 133-135.

[6] Meyer, Michael. (1985). Strindberg: A Biography. Oxford Lives ser. Oxford: Oxford UP. 1987. ISBN 019281995X

[7] Nurhayati, T. (2013). Error analysis of using punctuation in English text. (Conducted to students at semester six of English Department)

[8] Oshima, A \& Hogue, A. (1999). Writing academic english (3th ed.). New York: Addisson Wesley Longman.

[9] Robinson, P. (2002). "The Philosophy of Punctuation". Chicago. University of Chicago Press.

[10] Rumki, S. (2005). "How to Punctuate. Your Personal Writer: Custom. Research Papers". Essays and Term Papers

[11] Wilde, S. (1992). 'You kan red this!': Spelling and Punctuation for Whole Language. New Hampshire: Heinemann Educational Books

\section{AUTHORS}

Author - Tran Thi Yen, English lecturer, Thai Nguyen University of Education, Thai Nguyen, Vietnam, email: yentt@tnue.edu.vn

Correspondence Author - Tran Thi Yen, English lecturer, Thai Nguyen University of Education, Thai Nguyen, Vietnam, email: yentt@tnue.edu.vn. 